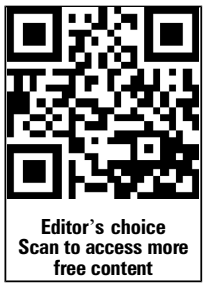

- Additional material is published online only. To view please visit the journal online (http://dx.doi.org/10.1136/ oemed-2013-101591).

${ }^{1}$ Department of Public Health, Erasmus MC, University Medical Center Rotterdam, Rotterdam, The Netherlands ${ }^{2}$ Department of Health Sciences, Community and Occupational Medicine, University Medical Center Groningen, University of Groningen, Groningen, The Netherlands

Correspondence to Rogier $M$ van Rijn, Department of Public Health, Erasmus MC, University Medical Center Rotterdam, Room Na-2202, P.0. Box 2040, Rotterdam 3000 CA The Netherlands; r.vanrijn@erasmusmc.n

Received 6 May 2013 Revised 30 September 2013 Accepted 9 October 2013 Published Online First 29 October 2013

\section{SLinked}

- http://dx.doi.org/10.1136/ oemed-2013-101945

To cite: van Rijn RM Robroek SJW, Brouwer S, et al. Occup Environ Med 2014;71:295-301.

\title{
Influence of poor health on exit from paid employment: a systematic review
}

\author{
Rogier M van Rijn, ${ }^{1}$ Suzan J W Robroek, ${ }^{1}$ Sandra Brouwer, ${ }^{2}$ Alex Burdorf ${ }^{1}$
}

\section{ABSTRACT}

The objective was to provide a systematic literature review on associations between poor health and exit from paid employment through disability pension, unemployment and early retirement, and to estimate the magnitude of these associations using meta-analyses. Medline and Embase databases were searched for longitudinal studies on the relationship between health measures and exit from paid employment. Randomeffects models were used to estimate the pooled effects. In total, 29 studies were included. Self-perceived poor health was a risk factor for transition into disability pension (relative risk (RR) 3.61; 95\% Cl 2.44 to 5.35), unemployment (RR 1.44; $95 \% \mathrm{Cl} 1.26$ to 1.65 ) and early retirement (RR $1.27 ; 95 \% \mathrm{Cl} 1.17$ to 1.38 ). Workers with mental health problems had an increased likelihood for transition into disability pension (RR 1.80; $95 \% \mathrm{Cl} 1.41$ to 2.31 ) or unemployment (RR $1.61 ; 95 \%$ $\mathrm{Cl} 1.29$ to 2.01). Chronic disease was a risk factor for transition into disability pension (RR 2.11; 95\% Cl 1.90 to 2.33 ) or unemployment (RR 1.31; $95 \% \mathrm{Cl} 1.14$ to 1.50), but not for early retirement. This meta-analysis showed that poor health, particularly self-perceived health, is a risk factor for exit from paid employment through disability pension, unemployment and, to a lesser extent, early retirement. To increase sustained employability it should be considered to implement workplace interventions that promote good health.

\section{INTRODUCTION}

In most Western countries a higher and prolonged labour force participation throughout a worker's life is necessary to safeguard the social and economic realities of an aging society. In order to achieve this ambition, governments are developing policies to stimulate labour force participation, particularly to keep workers in the workforce till older age. $^{1-4}$

The success of the developed policies depends on better understanding of the relationship between the impact of health on labour force participation. ${ }^{5}$ In the past few years several studies have demonstrated that health status may have a profound impact on the ability of workers to be actively engaged in paid employment and to prolong their meaningful contribution to a productive society. There is evidence from different longitudinal studies that poor health plays a role in exit from paid employment, due to disability pension, ${ }^{6-9}$ unemployment ${ }^{8} 10^{11}$ and early retirement. ${ }^{8} 1012$ A community based survey in the UK found evidence for health related job loss, especially in relation to musculoskeletal disorders and mental illness. ${ }^{13}$ Pedersen et $a l^{6}$ demonstrated that the risk of transition (from employment, unemployment or sickness absence) into disability pension was increased in those with a chronic disease. However, the risk of transition from work into unemployment was lower in those with a chronic disease. A prospective register study, with 15 years follow-up, in a cohort of nurses' aides found that risk factors for disability pension were mainly health related (eg, low back pain, sick leave spells), whereas economic factors (eg, income of spouse) influence the decision to retire early. ${ }^{14} \mathrm{~A}$ recent meta-analysis showed evidence for the association between important health behaviour factors and exit from paid employment. Obese, and to a lesser extent overweight, workers had an increased likelihood of exit from paid employment through disability benefit. Workers with lack of physical activity had an increased risk of disability benefit and unemployment. ${ }^{15}$

The impact of various health measures on exit from paid employment suggests that these measures differ between the main pathways of leaving the labour force, particularly between the involuntary (ie, disability pension, unemployment) and more voluntary routes (ie, early retirement) of exit from work. In order to understand and quantify the importance of different health measures on labour market exit pathways, the literature needs to be synthesised. Therefore, our aim was to provide a systematic literature review of the associations between different health measures and exit from paid employment through disability pension, unemployment and early retirement, and to estimate the magnitude of these associations using meta-analyses.

\section{MATERIALS AND METHODS \\ Literature search}

Comprehensive literature searches were conducted by the first author $(\mathrm{RMvR})$ in Medline, Embase and Web of Science (inception of databases to July 2013). The following keywords were used: health, work related, early-retirement, unemployment, disability pension, study design. The full search strategy is presented in online supplementary appendix I.

Based on title and abstract one reviewer (RMvR) selected the articles for full text appraisal. Two reviewers (RMvR, SJWR) independently selected articles for final inclusion. Each article had to fulfil all of the following criteria: (1) a health measure was described, (2) exit from paid employment was defined as receiving disability pension, unemployment or early retirement, (3) the association between health and exit from paid employment was expressed in an OR, relative risk (RR) or HR, or sufficient raw data was available to calculate associations, (4) a longitudinal study design was 
used, (5) the study had to involve a non-patient population, and (6) the article was published in a peer reviewed scientific journal written in English. A consensus method was used to resolve disagreements.

\section{Data extraction}

Relevant information on study population (age, gender, sample size), health measures, exit routes from paid employment and measures of associations with corresponding CI were extracted from the included articles by the first author (RMvR). The core findings in each article were expressed by measures of associations (OR, RR or HR) with corresponding 95\% CIs. Where possible, these associations were directly extracted from the original article. For articles in which this information was not presented, associations calculated using raw data were provided.

\section{Data analysis}

Heterogeneity of the included studies was determined using the $\mathrm{I}^{2}$ statistics, which indicates the percentage of total variation across studies that is due to heterogeneity rather than chance. ${ }^{16}$ Due to observed heterogeneity $\left(\mathrm{I}^{2}>50 \%\right.$ for disability pension) we conducted random-effects meta-analyses of the health effects on disability pension, unemployment and early retirement. Random-effects meta-analysis assumes that there are real differences between individual studies regarding the magnitude of the association between health determinants and exit from paid employment. It considers between-study and within-study variability. ${ }^{17}$ We used an Excel spreadsheet for pooling of RRs. ${ }^{18}$ In the meta-analysis we used measures of association that were adjusted for potential confounders, as presented in the original articles. An OR or HR was considered as approximation of RR when the frequency of outcome event was less than $10 \%$. A higher frequency of events will lead to an OR that substantially overestimated the RR. ${ }^{19}{ }^{20}$ Population attributable fractions (PAF) were calculated for significant determinants of exit from paid employment, using the formula $\mathrm{PAF}=\mathrm{Pe}(\mathrm{RR}-1) /(1+\mathrm{Pe}(\mathrm{RR}$ -1)) where Pe represents the prevalence of health problems in the study population. ${ }^{21}$

\section{RESULTS}

\section{Characteristics of the included studies}

Our search of the literature resulted in 2847 potentially relevant articles (figure 1). After title and abstract screening, 195 articles were retrieved for full text appraisal. Finally, 44 articles were included describing the influence of health on the risk of disability pension $(n=29)$, unemployment $(n=17)$ and early retirement $(n=9)$. Exclusion of articles was mainly due to lack of health measures $(n=49)$, absence of quantitative data $(n=44)$ or study population restricted to a specific patient group $(n=20)$. Several studies provided more than one measure of association and thus the sum of associations presented exceeds the number of included articles, for disability pension (self-perceived health: $n=13$, mental health: $n=29$, chronic disease: $n=42$ ), unemployment (self-perceived health: $\mathrm{n}=14$, mental health: $\mathrm{n}=15$, chronic disease: $\mathrm{n}=25$ ) and early-retirement (self-perceived health: $n=6$, chronic disease: $\mathrm{n}=22$ ). No studies were found on the association between mental health problems and exit through early retirement. In 12 articles no measure of association was presented, therefore we used the available raw data to calculate an OR with $95 \%$ CI. ${ }^{9} 1122-31$

\section{Disability pension}

Twenty-nine studies reported on the impact of health on the risk of disability pension (see online supplementary appendix II). ${ }^{7-9} \quad 14 \quad 23-28 \quad 30-48$ In 23 out of 29 studies the frequency of events was less than $10 \%$, therefore OR and HR were considered as an approximation of RR.

Self-perceived health was evaluated in 12 studies, ${ }^{7-}$ 9232426303637434648 presenting 13 associations. In all 12 studies self-perceived poor health was a significant risk factor for transition into disability pension (table 1 ) with a pooled RR of 3.61 (95\% CI 2.44 to 5.35), table 2 and figure 2. Poor health was measured on a 5 -point Likert scale, ${ }^{7-9} 264346$ a 4-point Likert scale 2348 or with the short-form health survey (SF-12 or SF-36). ${ }^{30}$ In eight studies poor health was defined as 'less than good health, ${ }^{7-9} 24 \quad 3043 \quad 4648$ whereas the other studies
Figure 1 Flow chart of the included studies.

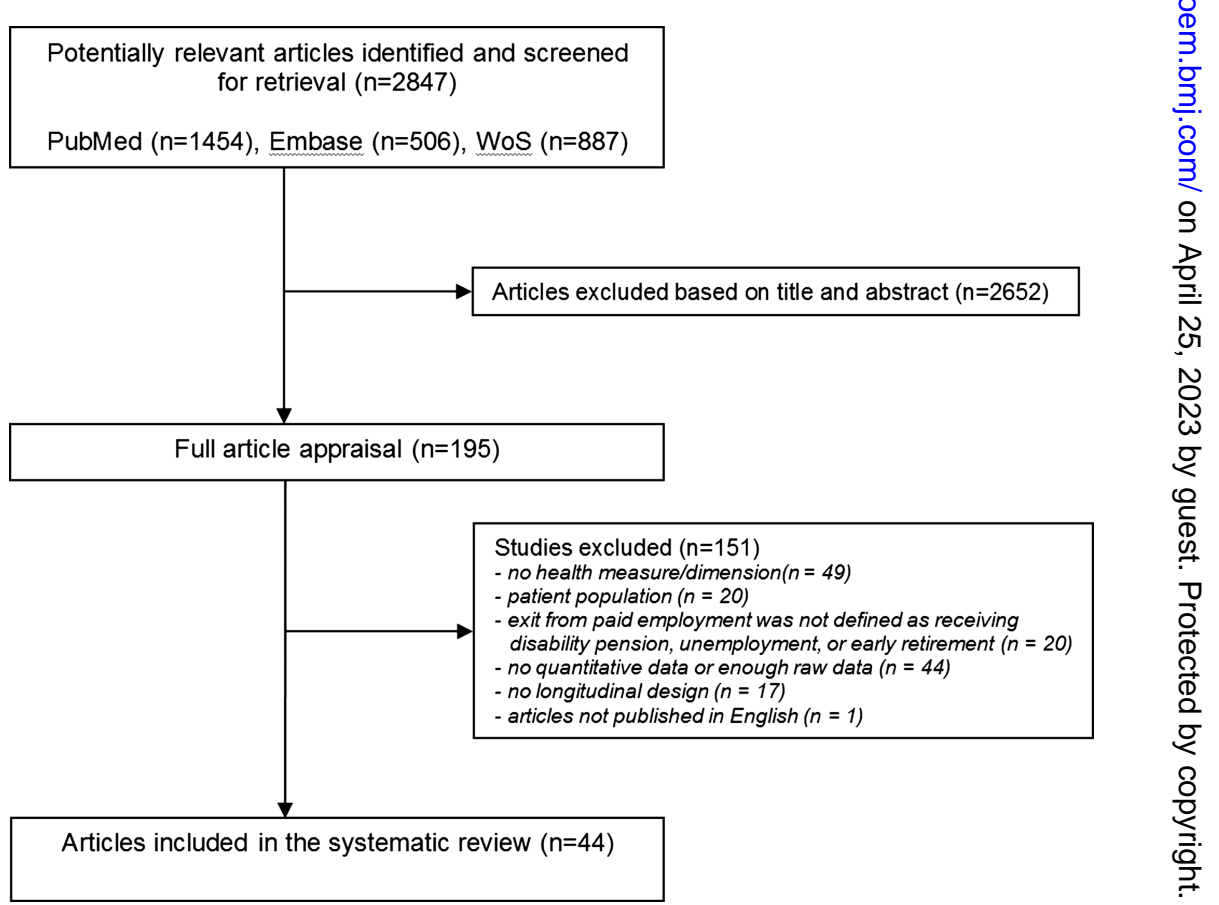


Table 1 Summary of associations between health measures and exit routes from paid employment as presented in the studies included in this systematic review

\begin{tabular}{|c|c|c|c|c|c|c|}
\hline & \multicolumn{2}{|l|}{ Disability pension } & \multicolumn{2}{|l|}{ Unemployment } & \multicolumn{2}{|l|}{ Early retirement } \\
\hline & No. of studies* & Range (RR/OR/HR) & No. of studies* & Range (RR/OR/HR) & No. of studies* & Range (RR/OR/HR) \\
\hline \multicolumn{7}{|l|}{ Self-perceived health } \\
\hline - All studies together & 13 & $1.30-7.38$ & 14 & $0.94-2.15$ & 6 & $1.17-1.55$ \\
\hline - Studies with significant associations & 13 & $1.30-7.83$ & 9 & $1.14-2.15$ & 4 & $1.20-1.55$ \\
\hline - Studies without significant associations & 0 & - & 5 & $0.94-1.49$ & 2 & $1.17-1.20$ \\
\hline \multicolumn{7}{|l|}{ Mental health } \\
\hline - All studies together & 29 & $0.49-7.56$ & 15 & $0.77-4.80$ & 0 & - \\
\hline - Studies with significant associations & 18 & $1.40-7.56$ & 10 & $1.57-4.80$ & & \\
\hline - Studies without significant associations & 11 & $0.49-2.23$ & 5 & $0.77-1.10$ & & \\
\hline \multicolumn{7}{|l|}{ Chronic disease } \\
\hline All studies together & 42 & $1.13-5.62$ & 25 & $0.90-2.20$ & 22 & $0.61-3.46$ \\
\hline - Studies with significant associations & 35 & $1.32-5.62$ & 4 & $1.35-2.11$ & 6 & $1.21-3.46$ \\
\hline - Studies without significant associations & 7 & $1.13-1.60$ & 21 & $0.90-2.20$ & 16 & $0.61-1.56$ \\
\hline \multicolumn{7}{|l|}{ MSD } \\
\hline All studies together & 25 & $1.14-4.64$ & 9 & $0.9-2.20$ & 4 & $0.90-1.76$ \\
\hline - Studies with significant associations & 23 & $1.50-4.64$ & 0 & - & 1 & 1.76 \\
\hline - Studies without significant associations & 2 & $1.14-1.60$ & 9 & $0.9-2.20$ & 3 & $0.91-1.56$ \\
\hline \multicolumn{7}{|l|}{ Respiratory } \\
\hline - All studies together & 5 & $1.80-3.92$ & 0 & - & 7 & $0.82-3.46$ \\
\hline - Studies with significant associations & 4 & $1.80-3.92$ & & & 1 & 3.46 \\
\hline - Studies without significant associations & 1 & 1.14 & & & 6 & $0.82-1.17$ \\
\hline \multicolumn{7}{|l|}{ Other } \\
\hline All studies together & 12 & $1.13-5.62$ & 16 & $0.84-2.11$ & 11 & $0.87-1.47$ \\
\hline - Studies with significant associations & 8 & $1.32-5.62$ & 4 & $1.35-2.11$ & 4 & $1.21-1.47$ \\
\hline - Studies without significant associations & 4 & $1.13-1.53$ & 12 & $0.84-1.52$ & 7 & $0.87-1.42$ \\
\hline
\end{tabular}

${ }^{*}$ Total number of studies within a category heading does not necessarily equal the number of studies included because some studies provide more than one association. MSD, musculoskeletal disorder.

defined poor health as 'less than fair health', ${ }^{23}$ 'less than moderate health ${ }^{26}$ or as a cut-off value $<40$ on the SF-36. ${ }^{36}$ Explorative analysis showed no influence of different cut-off values on pooled estimates of self-perceived poor health ('less than good health': RR 3.08, 95\% CI 1.94 to 4.88 ; 'less than fair/moderate health': RR 4.07, 95\% CI 1.70 to 9.71).

Seventeen studies investigated the influence of mental health problems on the risk of disability pension, presenting 29 associations (table 1). $.^{23} 24 \quad 2628 \quad 30-3840444547$ In 18 out of 29 associations mental health problems were a significant risk factor resulting in a pooled RR of 1.80 (95\% CI 1.41 to 2.31) across 29 associations (table 2).

In 13 studies the influence of chronic diseases on the risk of disability pension was evaluated, presenting 42 associations (table 1). ${ }^{14} 2324262734-36383941-43$ In 35 out of 42 associations chronic disease was a significant risk factor with a pooled RR of 2.11 (95\% CI 1.90 to 2.33) across the 42 associations. A large part of the associations reported on musculoskeletal disorders (25 out of 42), resulting in pooled RR of 2.23 (95\% CI 1.93 to 2.59 , table 2 ).

The PAF of self-perceived poor health, mental health problems and chronic diseases for transition into disability pension ranged from $3.9 \%$ to $76.8 \%$, from $0 \%$ to $48.6 \%$ and from $1.6 \%$ to $69.9 \%$, respectively (figure 3 ). Within the group of chronic diseases, we made a distinction between musculoskeletal disorders, respiratory diseases and other chronic disease, resulting in PAFs ranging from $1.2 \%$ to $69.9 \%$, from $1.7 \%$ to $14.5 \%$ and from $0.7 \%$ to $40.1 \%$, respectively.

Table 2 Pooled relative risks (RRs) of health measures for disability pension, unemployment and early retirement

\begin{tabular}{|c|c|c|c|c|c|c|c|c|c|}
\hline & \multicolumn{3}{|c|}{ Disability pension } & \multicolumn{3}{|c|}{ Unemployment } & \multicolumn{3}{|c|}{ Early retirement } \\
\hline & $\begin{array}{l}\text { No. of } \\
\text { studies* }\end{array}$ & $\begin{array}{l}\text { Sample } \\
\text { size }\end{array}$ & RR $(95 \%$ Cl) & $\begin{array}{l}\text { No. of } \\
\text { studies* }\end{array}$ & $\begin{array}{l}\text { Sample } \\
\text { size }\end{array}$ & RR (95\% Cl) & $\begin{array}{l}\text { No. of } \\
\text { studies* }\end{array}$ & $\begin{array}{l}\text { Sample } \\
\text { size }\end{array}$ & RR $(95 \%$ Cl) \\
\hline $\begin{array}{l}\text { Self-perceived } \\
\text { health }\end{array}$ & 13 & 111999 & 3.61 (2.44 to 5.35$)$ & 14 & 99617 & 1.44 (1.26 to 1.65$)$ & 6 & 32567 & 1.27 (1.17 to 1.38$)$ \\
\hline Mental health & 29 & 282459 & 1.80 (1.41 to 2.31$)$ & 15 & 20166 & 1.61 (1.29 to 2.01 ) & - & - & - \\
\hline Chronic disease & 42 & 66097 & 2.11 (1.90 to 2.33$)$ & 25 & 18003 & 1.31 (1.14 to 1.50$)$ & 22 & 16071 & 1.10 (0.99 to 1.21$)$ \\
\hline MSD & 25 & 58052 & 2.23 (1.93 to 2.59 ) & 9 & 5582 & 1.22 (1.01 to 1.48$)$ & 4 & 7534 & 1.23 (0.86 to 1.77$)$ \\
\hline Respiratory & 5 & 31208 & 2.35 (1.31 to 4.20$)$ & - & - & - & 7 & 6010 & 0.97 (0.89 to 1.04$)$ \\
\hline Other & 12 & 39637 & $2.22(1.63$ to 3.03$)$ & 16 & 13007 & 1.35 (1.14 to 1.60$)$ & 11 & 11759 & 1.12 (0.93 to 1.36$)$ \\
\hline
\end{tabular}

${ }^{*}$ Total number of studies within a determinant does not necessarily equal the number of studies included because some studies provide more than 1 association. MSD, musculoskeletal disorder. 


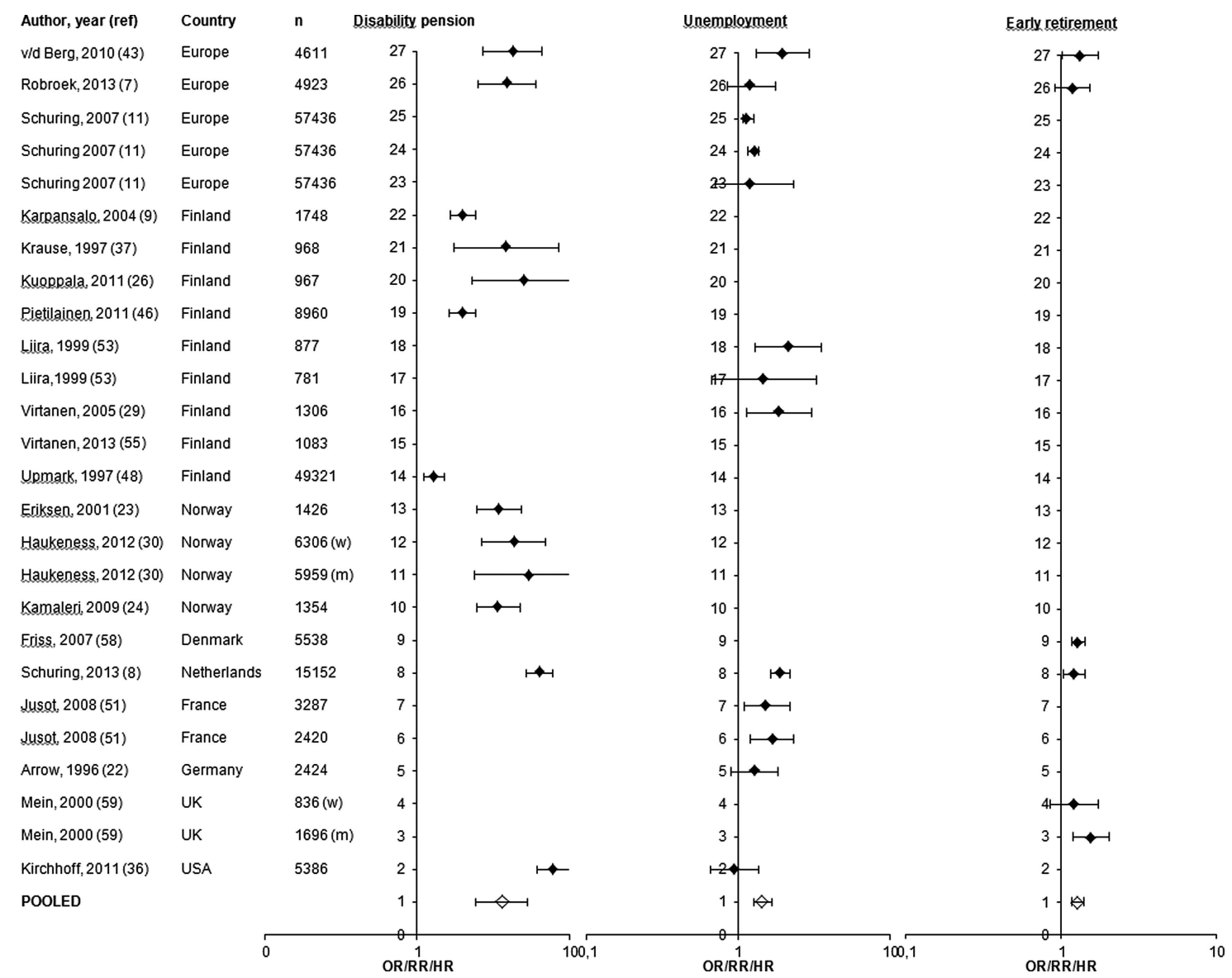

Figure 2 Association between self-perceived poor health and disability pension, unemployment and early retirement.

\section{Unemployment}

Seventeen studies investigated the influence of health on the risk of unemployment (see online supplementary appendix III). ${ }^{7} 81011222936394349-56$ In 14 out 17 studies the frequency of events was less than $10 \%$, therefore OR and HR were considered as an approximation of RR.

Self-perceived health was evaluated in 10 studies, presenting

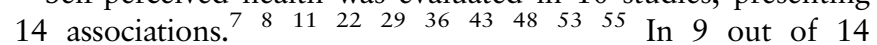

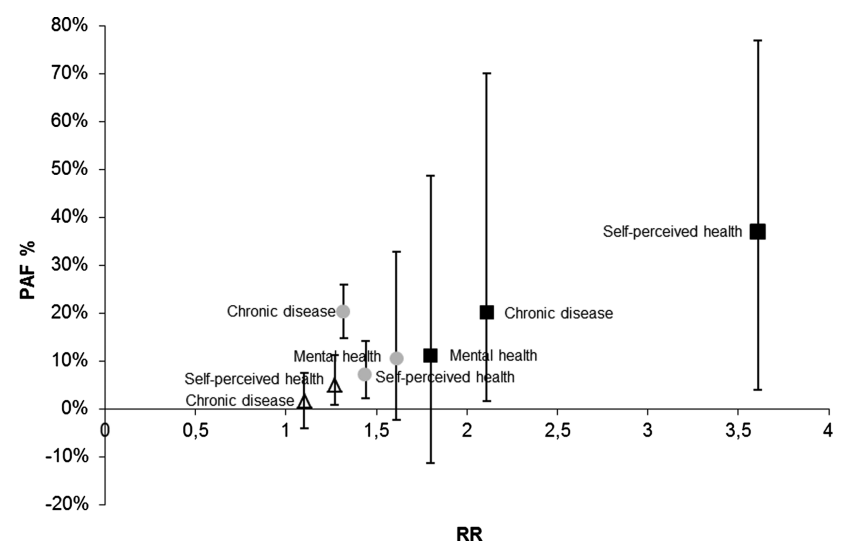

Figure 3 Relation between relative risk (RR) and population attributable fraction (PAF) for each health dimension and each pathway of leaving the labour force. Mean PAFs were calculated and reported with their range (error bars). $\mathbf{m}=$ disability pension, $0=$ unemployment, $\Delta=$ early retirement. associations self-perceived poor health was a significant risk factor for unemployment (table 1). Three studies presented results for different subgroups. Jusot et $a l^{51}$ reported no differences between men and women, poor health was found to be a precursor of unemployment in both genders. Liira and Leino-Arjas ${ }^{53}$ reported that a self-perceived poor health was a statistically significant risk factor for unemployment in construction workers (OR 2.15, 95\% CI 1.30 to 3.56), but not in forestry workers (OR $1.49,95 \%$ CI 0.67 to 3.28 ). Schuring et al ${ }^{11}$ found that self-perceived poor health was a statistically significant risk factor for unemployment in low and intermediate educated people, but not in highly educated people. Pooling of all studies resulted in a RR of 1.44 (95\% CI 1.26 to 1.65 , table 2).

Seven studies described the influence of mental health problems on the risk of unemployment, within a total of 15 associations (table 1). ${ }^{29} 364652-5456$ In 10 out of 15 associations mental health problems were a significant risk factor of unemployment with a pooled RR of 1.61 (95\% CI 1.29 to 2.01) across all 15 associations (table 2).

Seven studies investigated the influence of chronic diseases on unemployment presenting 25 associations with RR varying from 0.90 to 2.20 (table 1). ${ }^{22} 363943495253$ In 4 out of 25 associations a chronic disease was a significant risk factor for unemployment. In the meta-analysis the association between chronic disease and unemployment was statistically significant (pooled RR of $1.31,95 \%$ CI 1.14 to 1.50 ) (table 2).

The PAF of self-perceived poor health, mental health problems and chronic diseases for transition into unemployment ranged from $2.2 \%$ to $14.2 \%$, from $0.0 \%$ to $32.7 \%$ and from $0.0 \%$ to $9.9 \%$, respectively (figure 3 ). 


\section{Early retirement}

Nine studies investigated the influence of health on the risk of early retirement (see online supplementary appendix IV). ${ }^{7} 81014394357-59$ In six out of nine studies the frequency of events was less than $10 \%$, therefore OR and HR were considered as an approximation of RR.

Self-perceived health was evaluated in five studies, presenting six associations (table 1). 78435859 In four out of six associations self-perceived poor health was a significant risk factor of early retirement, resulting in a pooled RR of 1.27 (95\% CI 1.17 to 1.38 ) (table 2).

No studies reported on the association between mental health problems and exit through early retirement.

Five studies investigated the influence of chronic diseases on early retirement, presenting 22 associations (table 1). ${ }^{14} 39435759$ In 6 out of 22 associations a statistically significant association between chronic disease and early retirement was reported. Pooling of all five studies resulted in a RR of 1.10 (95\% CI 0.99 to 1.21) (table 2).

The PAF of self-perceived poor health and chronic diseases for transition into early retirement ranged from $0.8 \%$ to $11.1 \%$ and from $0.0 \%$ to $7.5 \%$, respectively (figure 3 ).

\section{DISCUSSION}

This meta-analysis shows that poor health increases the risk of exit from paid employment due to disability pension, unemployment and early retirement. The relative importance differed by pathway of exit from paid employment. The strongest associations were found for exit from paid employment through disability pension, followed by unemployment and, to a lesser extent, early retirement. Self-perceived poor health had a stronger effect on displacement through disability pension than mental health problems and presence of a chronic disease. The PAFs were largest for self-perceived poor health on disability pension, and for chronic diseases on disability pension and unemployment, indicating that good health and not having a chronic disease are important factors in maintaining paid employment.

Poor health, particularly self-perceived poor health, is a risk factor for exit from paid employment, especially through disability pension. The strong relation between self-perceived poor health and disability pension is not surprising, since health problems are a requirement for receiving a disability pension. However, eligibility of a disability pension does not depend on health problems alone, but also on individual, social, economic and legal factors. ${ }^{60} 61$ For example, the relationship between poor health and unemployment is consistent across Europe, but seems to vary across the type of welfare state regime. A study by Van der Wel et al found that the likelihood of non-employment was consistently lower in the Scandinavian welfare state regime type. The protective effect of welfare regimes reducing the risk of non- employment among workers with longstanding illness was largest in Scandinavian countries. ${ }^{62}$ Alternative measures to express the influence of health problems on exit from paid employment are, for example, lost working years due to health problems or working life expectancy. ${ }^{63} 64$

Perceived health shows stronger associations than mental health and chronic diseases with regard to exit from paid employment. In the majority of the studies in this review, perceived health (19 out of 19), mental health problems (21 out of 23) and chronic diseases (14 out of 19) were self-reported. Thus, it is reasonable to assume that the differences in magnitude of the associations between health measures and exit from paid employment are not due to systematic differences in ascertainment of these health measures. Studies which have included a variety of different health measures in the same study population endorse this assumption. For example, Van den Berg et al demonstrated higher associations for self-perceived poor health with disability pension (OR 4.24), unemployment (OR 1.96) and early retirement (OR 1.32) compared with the associations found for chronic diseases with OR 2.62, OR 1.30 and OR 1.28 , respectively. ${ }^{43}$ A study by Kuoppala et al showed that selfperceived poor health increased the risk of receiving a disability pension (OR 5.11, 95\% CI 2.31 to 11.28). Whereas, in the same study, a lower association was found between poor mental well-being and disability pension (OR 2.77, 95\% CI 1.32 to 5.80). ${ }^{26}$

The strong association between perceived health and exit from paid employment could be explained by the fact that selfperceived health partly reflects health-related quality of life, which is an integrated perception of health, including its biological, psychological and social dimensions. ${ }^{65}$ For example, important risk factors for poor health, like obesity and physical activity, are associated with exit from paid employment through disability benefit. ${ }^{15}$ In the majority of the studies perceived health was measured with a single question on a 4-point or a 5 -point scale. This restriction could be seen as a disadvantage. However, the assessment of self-perceived health has been found to be useful in evaluating health status in large epidemiological studies and has been shown to be a strong predictor of mortality in high as well as low socioeconomic groups. ${ }^{66}$

The impact of self-perceived poor health, mental health problems and chronic diseases is higher for the involuntary pathways (disability pension, unemployment) than for a more voluntary pathway (early retirement). For example, Van den Berg et al demonstrated that self-perceived poor health was significantly associated with disability pension (OR 4.24, 95\% CI 2.71 to 2.62 ) and unemployment (OR 1.96; 95\% CI 1.32 to 2.92), but was borderline significant with early retirement (OR $1.32 ; 95 \%$ CI 1.01 to 1.32$).{ }^{43}$ A study by Kirchhoff et al ${ }^{36}$ showed that self-perceived poor health significantly increased the risk of receiving disability pension (RR 7.83; 95\% CI 6.11 to 10.04 ). However, no association was found between poor health and exit from paid employment due to unemployment (RR 0.94 ; 95\% CI 0.65 to 1.37 ).

The mean PAFs of self-perceived poor health, mental health problems and chronic diseases for transition into disability pension were $36.9 \%, 11.1 \%$ and $20.6 \%$, respectively. The PAFs of chronic diseases ranged from $1.6 \%$ to $69.9 \%$ and, in general, larger PAF values were observed for studies with a higher prevalence of receiving disability pension.

The mean PAF of poor health for transition into unemployment varied between $4.0 \%$ for chronic diseases to $10.6 \%$ for mental health. For transition into early retirement, the mean PAF of self-perceived poor health and chronic diseases was $4.7 \%$ and $1.7 \%$, respectively. These findings suggest that poor health is a major risk factor for exit from paid employment, especially through disability pension. Thus, policies to promote sustainability of paid employment should incorporate health promotion.

The observational studies in this systematic review suggest that interventions aimed at promoting good health in the workplace may have an important contribution to increase sustained employability. There are indications that workplace health promotion improves self-perceived health and worker productivity, and will also lead to a decline in sick days. ${ }^{67-69}$ Besides, unhealthy lifestyle behaviours, physical and psychosocial work demands as well as 
organisational level factors play a role in exit from paid employment. $^{38}$ 70-72 Therefore, it should be considered to integrate health promotion activities with activities aimed at occupational health and safety to maintain a productive workforce.

A strength of this systematic review is the availability of enough studies of good quality (large sample size, longitudinal design) on the association between health measures and disability pension, unemployment and early retirement to conduct informative meta-analyses to estimate the magnitude of these associations. However, this study also has some limitations. First, the literature search may not be comprehensive enough, because publications in languages other than English were not included, and the search was limited to two computer-based bibliographical databases. Therefore, it might be possible that some useful studies were missed. Second, there is substantial variation between studies according to definitions of outcome and risk factor, follow-up period, and sex and age of the study population. However, in an explorative meta-regression analysis no determinants of heterogeneity were found. Third, the majority of studies are from Scandinavian countries, hampering the generalisability of findings to other countries. Consequently, the influence of type of welfare regime on the relationship between poor health and different pathways of leaving the labour market cannot be determined. Fourth, the calculation of exit from paid employment attributable to poor health was based on the methodology of PAF. ${ }^{21}$ This method may yield biased estimates when used with RR estimates adjusted for confounding. When the crude RR is greater than the adjusted risk, as was observed in the current review, the PAF may be underestimated. ${ }^{73}$ Last, although publication bias cannot be ruled out, there was no relation between the magnitude of risk estimates and their CIs of selfperceived health and mental health and the risk of exit from paid employment due to disability benefit, unemployment and early retirement. For chronic diseases larger risk estimates had larger CIs concerning exit from paid employment due to disability benefit, but not for unemployment and early retirement. Therefore, results about the influence of chronic diseases on the risk of disability benefit should be interpreted with some caution.

After summarising the literature it can be concluded that selfperceived poor health is a risk factor for exit from paid employment due to disability pension, unemployment and early retirement. The proportions of persons leaving the labour market that could be attributed to self-perceived poor health were $36.9 \%, 7.0 \%$ and $4.7 \%$, respectively for disability pension, unemployment and early retirement. Having mental health problems or a chronic disease was related with an increased risk of receiving disability pension or becoming unemployed, but not with early retirement. Primary preventive interventions focusing on promoting good health may contribute to sustained employability. Therefore, in order to maintain a productive workforce, it should be considered to integrate health promotion activities with activities aimed at occupational health and safety.

Correction notice This article has been corrected since it was published Online First. The relative risk values in the abstract have been updated.

Contributors RMvR: executed the systematic review, conducted the literature search, selected relevant articles for inclusion, performed the data extraction, analysed the data and wrote the manuscript. SJWR: helped conduct the literature search, selected relevant articles for inclusion and contributed to the content of the manuscript. SB and $A B$ initiated the study and contributed to the content of the article. All four authors made a substantial contribution to the information and material submitted and have read and approved the final version.

Funding This work was supported by the Netherlands Organisation for Health Research and Development (ZonMW, grant 208030012).

Competing interests None.
Provenance and peer review Not commissioned; externally peer reviewed.

\section{REFERENCES}

1 Cooke M. Policy changes and the labour force participation of older workers: evidence from six countries. Can J Aging 2006;25:387-400.

2 Doyle $Y$, McKee $M$, Rechel $B$, et al. Meeting the challenge of population ageing. BMJ 2009;339:b3926.

3 IImarinen JE. Aging workers. Occup Environ Med 2001;58:546-52.

4 von Bonsdorff ME, Huuhtanen P, Tuomi K, et al. Predictors of employees' early retirement intentions: an 11-year longitudinal study. Occup Med (Lond) 2010;60:94-100.

5 Cai L, Kalb G. Health status and labour force participation: evidence from Australia. Health Econ 2006;15:241-61.

6 Pedersen J, Bjorner JB, Burr $\mathrm{H}$, et al. Transitions between sickness absence, work, unemployment, and disability in Denmark 2004-2008. Scand J Work Environ Health 2012:38:516-26.

7 Robroek SJW, Schuring M, Croezen S, et al. Poor health, unhealthy behaviors, and unfavorable work characteristics influence pathways of exit from paid employment among older workers in Europe: a four year follow-up study. Scand J Work Environ Health 2013;39:125-33.

8 Schuring M, Robroek SJW, Otten FWJ, et al. The effect of ill health and socioeconomic status on labor force exit and re-employment: a prospective study with ten years follow-up in the Netherlands. Scand J Work Environ Health 2013;39:134-43.

9 Karpansalo M, Manninen P, Kauhanen J, et al. Perceived health as a predictor of early retirement. Scand J Work Environ Health 2004;30:287-92.

10 Cardano M, Costa G, Demaria M. Social mobility and health in the Turin longitudinal study. Soc Sci Med 2004;58:1563-74.

11 Schuring $M$, Burdorf $L$, Kunst $A$, et al. The effects of ill health on entering and maintaining paid employment: evidence in European countries. J Epidemiol Community Health 2007;61:597-604.

12 van den Berg TI, Elders LA, Burdorf A. Influence of health and work on early retirement. J Occup Environ Med 2010;52:576-83.

13 Solomon C, Poole J, Palmer KT, et al. Health-related job loss: findings from a community-based survey. Occup Environ Med 2007;64:144-9.

14 Jensen LD, Ryom PK, Christensen MV, et al. Differences in risk factors for voluntary early retirement and disability pension: a 15-year follow-up in a cohort of nurses' aides. BMJ Open 2012;2:e000991.

15 Robroek SJ, Reeuwijk KG, Hillier FC, et al. The contribution of overweight, obesity, and lack of physical activity to exit from paid employment: a meta-analysis. Scand J Work Environ Health 2013;39:233-40.

16 Higgins JP, Thompson SG, Deeks JJ, et al. Measuring inconsistency in meta-analyses. BMJ 2003;327:557-60.

17 Higgins J, Green S, eds. Cochrane Handbook for Systematic Reviews of Interventions Version 5.1.0 [updated March 2011]. The Cochrane Collaboration. 2011. http:/l www.cochrane-handbook.org

18 Fleiss JL. The statistical basis of meta-analysis. Stat Methods Med Res 1993;2:121-45.

19 Davies HT, Crombie IK, Tavakoli M. When can odds ratios mislead? BMJ 1998:316:989-91.

20 McNutt LA, Wu C, Xue X, et al. Estimating the relative risk in cohort studies and clinical trials of common outcomes. Am J Epidemiol 2003;157:940-3.

21 Hennekens C, Buring B, Mayrent S. Epidemiology in medicine. Boston: Lippincott Williams \& Wilkins, 1987.

22 Arrow JO. Estimating the influence of health as a risk factor on unemployment: a survival analysis of employment durations for workers surveyed in the German Socio-Economic Panel (1984-1990). Soc Sci Med 1996:42:1651-9.

23 Eriksen W, Natvig B, Bruusgaard D. Sleep problems: a predictor of long-term work disability? A four-year prospective study. Scand J Public Health 2001;29:23-31.

24 Kamaleri Y, Natvig B, Ihlebaek CM, et al. Does the number of musculoskeletal pain sites predict work disability? A 14-year prospective study. Eur J Pain 2009;13:426-30.

25 Koivumaa-Honkanen $\mathrm{H}$, Koskenvuo M, Honkanen RJ, et al. Life dissatisfaction and subsequent work disability in an 11-year follow-up. Psychol Med 2004;34:221-8.

26 Kuoppala J, Lamminpaa A, Vaananen-Tomppo I, et al. Employee well-being and sick leave, occupational accident, and disability pension: a cohort study of civil servants. J Occup Environ Med 2011;53:633-40.

27 Natvig B, Eriksen W, Bruusgaard D. Low back pain as a predictor of long-term work disability. Scand J Public Health 2002;30:288-92.

28 Sivertsen B, Overland S, Neckelmann D, et al. The long-term effect of insomnia on work disability: the HUNT-2 historical cohort study. Am J Epidemiol 2006;163:1018-24

29 Virtanen P, Vahtera J, Kivimaki M, et al. Labor market trajectories and health: a four-year follow-up study of initially fixed-term employees. Am J Epidemiol 2005; 161:840-6.

30 Haukenes I, Gjesdal S, Rortveit G, et al. Women's higher likelihood of disability pension: the role of health, family and work. A 5-7 years follow-up of the Hordaland Health Study. BMC Public Health 2012;12:720. 
31 Wedegaertner F, Arnhold-Kerri S, Sittaro NA, et al. Depression- and anxiety-related sick leave and the risk of permanent disability and mortality in the working population in Germany: a cohort study. BMC Public Health 2013:13:145.

32 Ahola K, Gould R, Virtanen M, et al. Occupational burnout as a predictor of disability pension: a population-based cohort study. Occup Environ Med 2009;66:284-90; discussion 2-3.

33 Ahola K, Toppinen-Tanner S, Huuhtanen $\mathrm{P}$, et al. Occupational burnout and chronic work disability: an eight-year cohort study on pensioning among Finnish forest industry workers. J Affective Disord 2009;115:150-9.

34 Ahola $\mathrm{K}$, Virtanen $\mathrm{M}$, Honkonen $\mathrm{T}$, et al. Common mental disorders and subsequent work disability: a population-based Health 2000 Study. J Affective Disord 2011:134:365-72.

35 Alexanderson K, Kivimaki M, Ferrie JE, et al. Diagnosis-specific sick leave as a long-term predictor of disability pension: a 13-year follow-up of the GAZEL cohort study. J Epidemiol Community Health 2012;66:155-9.

36 Kirchhoff AC, Krull KR, Ness KK, et al. Physical, mental, and neurocognitive status and employment outcomes in the childhood cancer survivor study cohort. Cancer Epidemiol Biomarkers Prev 2011;20:1838-49.

37 Krause N, Lynch J, Kaplan GA, et al. Predictors of disability retirement. Scand J Work Environ Health 1997;23:403-13.

38 Lund T, Csonka A. Risk factors in health, work environment, smoking status, and organizational context for work disability. Am J Ind Med 2003;44:492-501.

39 Lund T, Iversen L, Poulsen KB. Work environment factors, health, lifestyle and marital status as predictors of job change and early retirement in physically heavy occupations. Am J Ind Med 2001;40:161-9.

40 Overland S, Glozier N, Sivertsen B, et al. A comparison of insomnia and depression as predictors of disability pension: the HUNT Study. Sleep 2008;31:875-80.

41 Ropponen A, Narusyte J, Alexanderson K, et al. Stability and change in health behaviours as predictors for disability pension: a prospective cohort study of Swedish twins. BMC Public Health 2011:11:678.

42 Rothenbacher $D$, Arndt V, Fraisse $E$, et al. Early retirement due to permanent disability in relation to smoking in workers of the construction industry. J Occup Environ Med 1998;40:63-8

43 van den Berg $T$, Schuring $M$, Avendano $M$, et al. The impact of ill health on exit from paid employment in Europe among older workers. Occup Environ Med 2010;67:845-52.

44 Bultmann U, Christensen KB, Burr $\mathrm{H}$, et al. Severe depressive symptoms as predictor of disability pension: a 10-year follow-up study in Denmark. Eur J Public Health 2008; 18:232-4.

45 Karpansalo M, Kauhanen J, Lakka TA, et al. Depression and early retirement: prospective population based study in middle aged men. J Epidemiol Community Health 2005;59:70-4.

46 Pietilainen 0, Laaksonen M, Rahkonen 0, et al. Self-Rated Health as a Predictor of Disability Retirement-The Contribution of III-Health and Working Conditions. PLoS ONE 2011:6:e25004.

47 Rai D, Kosidou K, Lundberg M, et al. Psychological distress and risk of long-term disability: population-based longitudinal study. J Epidemiol Community Health 2012;66:586-92.

48 Upmark M, Hemmingsson T, Romelsjo A, et al. Predictors of disability pension among young men-the role of alcohol and psychosocial factors. Eur J Public Health 1997;7:20-8.

49 Bildt C, Michelsen H. Occupational conditions exceed the importance of non-occupational conditions and ill health in explaining future unemployment among women and men. Arch Womens Ment Health 2003:6:115-26.

50 Earle A, Heymann SJ. What causes job loss among former welfare recipients: the role of family health problems. J Am Med Womens Assoc 2002:57:5-10.

51 Jusot $F$, Khlat M, Rochereau T, et al. Job loss from poor health, smoking and obesity: a national prospective survey in France. J Epidemiol Community Health 2008:62:332-7.
52 Leino-Arjas $\mathrm{P}$, Liira J, Mutanen $\mathrm{P}$, et al. Predictors and consequences of unemployment among construction workers: prospective cohort study. BMJ 1999:319:600-5.

53 Liira J, Leino-Arjas P. Predictors and consequences of unemployment in construction and forest work during a 5-year follow-up. Scand J Work Environ Health 1999:25:42-9.

54 Thielen K, Nygaard E, Andersen I, et al. Employment consequences of depressive symptoms and work demands individually and combined. Eur J Public Health. Published Online First: 1 Feb 2013. doi:10.1093/eurpub/ckt011

55 Virtanen $\mathrm{P}$, Janlert $\mathrm{U}$, Hammarstrom A. Health status and health behaviour as predictors of the occurrence of unemployment and prolonged unemployment. Public Health 2013:127:46-52.

56 Whooley MA, Kiefe $\mathrm{Cl}$, Chesney MA, et al. Depressive symptoms, unemployment, and loss of income-The CARDIA study. Arch Intern Med 2002;162:2614-20.

57 Ames RG, Trent RB. Respiratory impairment and symptoms as predictors of early retirement with disability in US underground coal miners. Am J Public Health 1984;74:837-8.

58 Friis K, Ekholm 0, Hundrup YA, et al. Influence of health, lifestyle, working conditions, and sociodemography on early retirement among nurses: the Danish Nurse Cohort Study. Scand J Public Health 2007;35:23-30.

59 Mein G, Martikainen P, Stansfeld SA, et al. Predictors of early retirement in British civil servants. Age Ageing 2000;29:529-36.

60 Ostby KA, Orstavik RE, Knudsen AK, et al. Health problems account for a small part of the association between socioeconomic status and disability pension award. Results from the Hordaland Health Study. BMC Public Health 2011;11:12.

61 Stattin M, Jarvholm B. Occupation, work environment, and disability pension: a prospective study of construction workers. Scand J Public Health 2005:33:84-90

62 van der Wel KA, Dahl E, Thielen K. Social inequalities in "sickness": does welfare state regime type make a difference? A multilevel analysis of men and women in 26 European countries. Int J Health Serv 2012;42:235-55.

63 Knudsen AK, Overland S, Hotopf $M$, et al. Lost working years due to mental disorders: an analysis of the Norwegian disability pension registry. PLoS One 2012;7:e42567.

64 Lacaille D, Hogg RS. The effect of arthritis on working life expectancy. J Rheumatol 2001:28:2315-19.

65 Wilson IB, Cleary PD. Linking clinical variables with health-related quality of life. A conceptual model of patient outcomes. JAMA 1995;273:59-65.

66 Burstrom B, Fredlund P. Self rated health: Is it as good a predictor of subsequent mortality among adults in lower as well as in higher social classes? J Epidemiol Community Health 2001;55:836-40.

67 Burton WN, McCalister KT, Chen CY, et al. The association of health status, worksite fitness center participation, and two measures of productivity. J Occup Environ Med 2005;47:343-51.

68 Lechner $\mathrm{L}$, de Vries $\mathrm{H}$, Adriaansen $\mathrm{S}$, et al. Effects of an employee fitness program on reduced absenteeism. J Occup Environ Med 1997;39:827-31.

69 Rongen A, Robroek SJW, Van Lenthe FJ, et al. Workplace health promotion: a meta-analysis of effectiveness. Am J Prev Med 2013;44:406-15.

70 Alavinia SM, Molenaar D, Burdorf A. Productivity loss in the workforce: associations with health, work demands, and individual characteristics. Am J Ind Med 2009;52:49-56

71 Albertsen $\mathrm{K}$, Lund $\mathrm{T}$, Christensen $\mathrm{KB}$, et al. Predictors of disability pension over a 10-year period for men and women. Scand J Public Health 2007;35:78-85.

72 van den Heuvel SG, Geuskens GA, Hooftman WE, et al. Productivity loss at work; health-related and work-related factors. J Occup Rehabil 2010;20:331-9.

73 Darrow LA, Steenland NK. Confounding and bias in the attributable fraction. Epidemiology 2011;22:53-8 